\title{
RELAÇÕES DE PODER E ESTRATÉGIAS DE RESISTÊNCIA NO CONTO $O$ PRESO, DE MOREIRA CAMPOS: UMA ANÁLISE NA PERSPECTIVA DA GENEALOGIA FOUCAULTIANA
}

\author{
POWER RELATIONS AND RESISTANCE STRATEGIES IN THE COUNT THE \\ PRISIONER, OF MOREIRA CAMPOS: AN ANALYSIS IN THE PERSPECTIVE OF \\ FOUCAULTIAN GENEALOGY
}

Wellington Gomes de Souza ${ }^{1}$ Francisco Vieira da Silva ${ }^{2}$

Recebido em: 29 set. 2018

Aceito em: 20 jan. 2019

DOI: 10.26512/aguaviva.v4i1.22112

RESUMO: O artigo que aqui se apresenta está pautado na identificação das relações de poder existentes entre os personagens da narrativa $O$ preso, de autoria do contista cearense Moreira Campos. Nesse contexto, o objetivo proposto é analisar a constituição dos sujeitos no conto, a partir das relações de poder que se estabelecem no desenvolvimento do enredo. Para fundamentar esta abordagem, buscou-se subsídios, basicamente, em Foucault (1976; 1987; 2008; 2009), que trata das questões inerentes à constituição dos sujeitos, mediante o poder que lhes é conferido por diversas instâncias da sociedade e pelas relações de poder que se estabelecem, oriundas de sua capilaridade. Da mesma forma, trata-se da prisão, enquanto estratégia de poder disciplinar. Como procedimento metodológico, percorreu-se com a leitura analítica do conto, concatenando-a com os aspectos teóricos inerentes aos escritos foucaultianos. Como resultado, percebeu-se que as relações de poder são determinadas pelo lugar social de cada um, o que converge para a constituição dos sujeitos. Dessa forma, entende-se que a análise das relações de poder entre os sujeitos confere uma visão mais aguçada acerca de suas lutas para a constituição da subjetividade.

Palavras-chave: Conto; Sujeito; Poder

\begin{abstract}
: this article presented here is based on the identification of power relations existents between the characters of the narrative The prisioner, of authorship Ceará State writer Moreira Campos. In this context, the objective propused is to analyze the constituition of the subjects in the count, based on the power relations that are established in the

1 Doutorando do Programa de Pós-Graduação em Letras (PPGL) da Universidade do Estado do Rio Grande do Norte (UERN). Professor da rede estadual da educação do Ceará. E-mail: wellington83souza@gmail.com

2 Docente da Universidade Federal Rural do Semi-Árido (UFERSA), do Programa de Pós-Graduação em Letras (PPGL) da Universidade do Estado do Rio Grande do Norte (UERN) e do Programa de Pós-Graduação em Ensino (POSENSINO) da associação entre a Universidade do Estado do Rio Grande do Norte (UERN), a Universidade Federal Rural do Semi-Árido (UFERSA) e o Instituto Federal de Educação, Ciência e Tecnologia do Rio Grande do Norte (IFRN). E-mail: francisco.vieiras@ufersa.edu.br.
\end{abstract}


development of the plot. To support this approach, we sought subsidies, basically, em Foucault $(1976 ; 1987 ; 2008 ; 2009)$, that treats of the questions related in the constituition of subjects, through the power conferred on them by various instances of society and by power relations that established, deriving from their capillarity. In the same way, it is prision as a strategy of disciplinary power. As a methodological procedure, the analytic reading of the count was traced to the theoretical aspects inherent to the Foucaultian writings. As a result, it was perceived that power relations are determined by the social place of each, which converges to the constitution of the subjects. Thus, it is understood that the analysis of the power relations between the subjects gives a sharper view of their struggles for the constitution of subjectivity.

Keywords: Count; Subject; Power.

\section{INTRODUÇÃO}

As relações de poder consistem em algo de suma importância para a constituição dos sujeitos na sociedade. Em diversas instâncias sociais, há indivíduos que exercem determinado poder em relação a outros, que se tornam seus parceiros nessas relações. Nesse cenário, travam-se lutas e oferecem-se resistências, que nada mais são do que reações em relação às ações do outro.

Com isso, podemos afirmar que as relações de poder são atinentes à ideia de resistência. Assim, não há o embate senão em um campo estratégico dessas relações. Dessa forma, o poder está relacionado ao lugar social dos indivíduos e o estabelecimento dessas relações de poder também. Podemos enfatizar que há várias relações sociais que são relações de poder e, consequentemente, terreno fértil para a luta entre a tentativa de objetivação dos corpos e entre a constituição da subjetividade.

Portanto, é importante discorrermos sobre como essas relações se estabelecem e como elas atuam na constituição dos sujeitos, enquanto seres sociais que são regidos por diversos poderes na sociedade, nas mais variadas instâncias.

Por isso, nosso objetivo é analisar como se estabelecem essas relações de poder, mediante a observância das personagens do conto $O$ preso, do contista cearense Moreira Campos. Isso porque, no conto em questão, é perceptível a criação de um cenário de resistência em relação às estratégias de poder empregadas pelos indivíduos.

Para fundamentar nossa abordagem, ancoraremos a discussão nos escritos foucaultianos acerca do Sujeito e o poder, bem como em sua aula de 17 de março de 1976, intitulada como Em defesa da sociedade. Basearemo-nos, também, em Vigiar e Punir (1987) 
e na Microfísica do Poder (2008), para tratarmos dos aspectos atinentes à genealogia do poder e à prisão como estratégia de poder disciplinar e restaurador de condutas.

Os procedimentos metodológicos foram pautados na leitura analítica do conto e o encadeamento da análise com os aspectos teóricos de Foucault. Assim, buscaremos embasar a nossa abordagem levando em consideração os discursos presentes na narrativa.

Este artigo encontra-se organizado em duas seções, além desta introdução. Na seção que segue, trataremos das questões inerentes à constituição dos sujeitos, levando em consideração o lugar social dos indivíduos, que permite o estabelecimento das relações de poder e a criação de um contexto de luta e resistência em prol da preservação da subjetividade desses sujeitos.

Posteriormente, apresentaremos o enredo da narrativa em pauta com o intuito de concatenar os fatos narrados com os aspectos teóricos atinentes ao estabelecimento das relações de poder que permeiam a sociedade.

\section{As relações de poder e a constituição do sujeito}

A abordagem que pretendemos desenvolver é concernente à ideia de que a constituição dos sujeitos é oriunda do poder que lhes é conferido em determinadas instâncias da sociedade, que os fazem agir sobre outros sujeitos desse mesmo contexto social. Em outras palavras, podemos destacar o aspecto relacional que permeia as estratégias de poder, mediante a consideração de diversos pontos. Com isso, é importante ressaltar que as relações de poder não se limitam à oposição binária entre dominado e dominador, pois Prado Filho (2017) destaca que, ao passo que se estabelecem relações de poder entre os indivíduos, cria-se um campo de resistência que é oriundo dessas relações.

Portanto, vale dizer, nesse contexto, que “[...] todos os tipos de relação - sociais, econômicas, afetivas, sexuais, de conhecimento - são relações de poder [...]” (PRADO FILHO, 2017, p. 320). Diante dessas relações, podemos observar a construção de possibilidades diversas de resistência. Ao pegarmos como exemplo as relações de poder concernentes ao sexo, é perceptível o poder que se atribui ao sexo masculino, tendo em vista o caráter patriarcal da nossa sociedade, mas também temos a luta do sexo feminino e a resistência que objetiva a construção de uma relação igualitária. 
Podemos dizer, destarte, que esse contexto é bastante complexo e responsável pela produção dos indivíduos na sociedade. A esse respeito, o autor supracitado apresenta aspectos concernentes à constituição dos sujeitos, que ocorre da seguinte forma:

[...] Pela aplicação, inicialmente, de práticas de separação e individualização de corpos; depois, pelo acionamento de jogos de identificação, que marcam cada indivíduo, ligando-o à sua identidade; em seguida, pela aplicação de técnicas de exame, possibilitando a comparação e classificação entre eles; e ainda, pela aplicação do poder da norma, marcando, incluindo ou excluindo, patologizando e corrigindo desvios, normalizando e regulando suas condutas individuais. Individualização + identificação + comparação + normalização $=$ conjuntos de práticas articuladas, tecnologias solidárias, camadas superpostas, etapas sucessivas da produção de indivíduos em nossa cultura. (PRADO FILHO, 2017, p. 316-317)

Diante disso, é possível afirmar que a constituição dos sujeitos é fruto do poder exercido sobre eles, e suas respectivas tecnologias, além da resistência que se instala nessas relações. Assim, a constituição do sujeito filho, por exemplo, é inerente ao poder familiar que é estabelecido pelos pais, pelo menos em tese. Da mesma forma, a constituição do sujeito pertencente a uma sociedade diz respeito ao poder regulamentador, bem como as normas que permeiam a conduta social de cada um.

Em outras palavras, são as relações de poder que constituem os sujeitos. Nesse contexto, Foucault (2009) menciona o seguinte:

[...] se falamos do poder das leis, das instituições ou das ideologias, se falamos de estruturas ou de mecanismos de poder, é apenas na medida em que supomos que "alguns" exercem um poder sobre outros. O termo "poder" designa relações entre "parceiros" [...]. (FOUCAULT, 2009, p. 240).

O que o autor frisa vai ao encontro da ideia de que os sujeitos são de certa forma moldados pelos poderes com os quais eles mantêm contato nas diversas instâncias sociais, pois, muitas vezes, estão sujeitos a esses poderes. É válido ressaltar, também, que as relações de poder que se estabelecem entre os sujeitos, geralmente, não são consensuais, apesar de ocorrerem entre homens livres. 
Apesar da resistência que se instala, juntamente com o estabelecimento das relações de poder e da liberdade dos indivíduos para atuarem nessa perspectiva, é importante ressaltar a transformação exercida nessas relações. Valemo-nos, assim, do que diz Foucault (1987, p. 74):

[...] quando penso na mecânica do poder, penso em sua forma capilar de existir, no ponto em que o poder encontra o nível dos indivíduos, atinge seus corpos, vem se inserir em seus gestos, suas atitudes, seus discursos, sua aprendizagem, sua vida quotidiana.

Diante do que diz o autor, podemos citar a prisão como uma engrenagem dessa mecânica de poder, sobretudo com o intuito de disciplinar e restaurar a conduta dos indivíduos. A prisão, dessa forma, consiste em uma estratégia desse poder para atingir e modificar os corpos, o que demonstra a sua capilaridade.

$\mathrm{Na}$ verdade, há condutas ativas que são estabelecidas entre os parceiros dessas relações de poder. Da mesma forma, há o pareamento de ações e reações entre os sujeitos nessas relações de poder, com base nas condições de cada um, enquanto sujeitos do outro e de si.

Isso diz respeito ao pensamento foucaultiano sobre a genealogia do poder, como podemos analisar no que segue:

[...] Foucault propôs e aplicou um método de análise de subjetivações, ou de relações do sujeito consigo mesmo, que compõem uma ética, um governo sobre si mesmo. E nesta passagem de uma genealogia das práticas de poder a uma genealogia das relações éticas, mais uma vez, deslocamento: de perspectiva - dos jogos de objetivação dos sujeitos para práticas de subjetivação - e de objeto, da produção do/pelo outro para as relações e trabalhos consigo mesmo. (PRADO FILHO, 2017, p. 312).

É importante ressaltar que, segundo Foucault (2009), as relações de poder são pautadas na liberdade de cada um para que as condutas sejam efetivas no estabelecimento dessas relações. Assim, por exemplo, a escravidão não seria uma relação de poder, mas sim de submissão, segundo o autor.

Dessa forma, é necessário respeitar a linha tênue que separa o estabelecimento das relações de poder na sociedade e a prática de submissão que pode cercear a liberdade dos 
sujeitos. Valemo-nos, então, dos pontos estabelecidos pelo autor supracitado para a análise dessas relações, que são: o sistema das diferenciações que possibilitam o agir sobre a ação do outro; o tipo de objetivos perseguidos pelos que agem sobre a ação do outro; as modalidades instrumentais de ação; as formas de institucionalização; e, por último, os graus de racionalização em relação ao funcionamento das relações de poder.

Em síntese, podemos dizer que as relações de poder consistem em relações em que as ações e as reações são permeadas pela ideia de resistência, conforme já destacamos. Isso ocorre no sentido de promover transformações de dadas realidades concernentes aos sujeitos que ocupam determinados lugares sociais.

\section{Relações de poder e estratégias de resistência no conto}

O preso, objeto de nossa análise, é pautado em alguns aspectos inerentes à conduta social e moral, que permeiam a sociedade de maneira geral. Nesse sentido, é importante explanar sobre o teor do enredo, no sentido de entendermos como ocorrem as relações entre os sujeitos, no que elas consistem e qual a sua importância para o desenvolvimento do conto. Por isso, apresentaremos, brevemente, os fatos presentes na narrativa de Moreira Campos. ${ }^{3}$

A princípio, temos uma situação em que Dr. Antero, advogado que viera à cidade resolver algumas questões de terras, reclamava da inércia relativa ao desenvolvimento do local. Enquanto isso, seus anfitriões, o tabelião do lugarejo e o farmacêutico, jogavam gamão:

Ao lado, o tabelião, na blusa de pijama e chinelos, jogava gamão com o farmacêutico, figura seca e encurvada, num grande nariz.

- Quina, compadre! - disse o serventuário, esfregando os pés um no outro embaixo da cadeira. - Dou-lhe uma, dou-lhe duas. Tire esta.

$\mathrm{O}$ farmacêutico recolheu a pedra num silêncio concentrado. Homem de poucas palavras, quando perdia ficava mudo e aborrecia as expansões do outro.

Dr. Antero tornou a estender a vista sobre a praça. Tirou o charuto melado da boca, cuspindo peles de fumo:

- Há vinte anos que conheço esta terra, e não muda! Já vinte! A mesma coisa. Agora pior, parece. (CAMPOS, s.d.)

3 Moreira Campos foi Professor de letras na UECE e Pró-Reitor da UFC. Um dos nomes mais indicados para o vestibular da UFC, membro da Academia Cearense de Letras, o poeta cronista integrou o Grupo Clã, movimento modernista da literatura cearense. Informação disponível em: http://www.radiouniversitariafm.com.br/audios/conto-o-preso-de-moreira-campos/. Acesso em 08 jan. 2019. 
Porém, o clima de tédio é dissipado quando dois soldados surgem trazendo um homem descrito como um velho mirrado, de pele escura, que vinha puxando um jumento. Inácio, o preso custodiado pelos policiais, era vilipendiado por alguns moleques pelo fato de ter um caroço. Diante disso, ele acertou um dos meninos na altura da testa com um pedaço de madeira. Por isso, estava nessa situação.

Depois de saber do que se tratava, Dr. Antero recomenda a soltura do homem. Contudo, ao saber que vítima era filha do juiz da cidade, Dr. Targino, o advogado muda de ideia e mantém Inácio preso, apesar de suas súplicas. Isto é, a individualização da vítima é que torna o ato de Inácio passível de punição.

Ao longo de seus pedidos para ser solto e de sua defesa, Inácio pronunciava a seguinte frase: "Me soltem que eu não tenho paciência de ser preso". Isso era motivo de zombaria dos presentes, pois na visão dessas pessoas, ele, um pobre homem, sujo, negro, não teria o direito de proferir tais palavras e de exigir a sua soltura. É o que vemos no que se segue:

Riram muito com a frase. O tabelião divertia-se, vermelho e todo sacudido pela novidade. Sungava as calças com os cotovelos e comentava em volta de um para outro:

- Hein? Hein? Que tal? Esta é boa! "Não tenho paciência...". Como é que ele diz? (CAMPOS, s.d.)

Apesar de toda a argumentação de Inácio para não ser preso, ele fora conduzido até a cadeia. Ali, ele reflete sobre o seu papel social, a sua conduta enquanto sujeito exemplar, espelho para os filhos que era, e via, no fato de ser preso, uma vergonha para a família e uma desonra a seus preceitos.

Nesse contexto, Inácio solicita a um menino que passava em frente a sua cela, que dava para a rua e de onde ele podia avistar o seu jumento, que pegue a corda que prendia o animal e lhe entregue. Com essa corda, então, Inácio comete suicídio.

Com a morte de Inácio, a sua súplica torna-se um flagelo para a consciência daqueles que riam do pobre homem. É o que podemos analisar no trecho que segue:

A frase tomou conta das consciências. Pelas nove horas, o tabelião, ao assinar uma escritura, ainda a repetia, arrastando a pena no papel:

- "Me soltem, que eu não tenho paciência de ser preso".

Dona Belinha misturava-a com o caldo na cozinha, enquanto girava a colher de pau. 0 farmacêutico triturava-a com o pó que mexia no almofariz. 
Já o trem de Dr. Antero partira. Tentou a leitura de uma revista, que atirou de lado. - "Me soltem, que eu não tenho paciência de ser preso".

Ergueu-se, foi ao carro-restaurante, tornou à sua cadeira. Olhou pela janela. Um açude, bois que pastavam, carnaubeiras e, logo a seguir, a ponte de ferro. As rodas do carro matraqueavam nos trilhos num ritmo que reproduzia a frase inesperada:

- "Me soltem, que eu não tenho paciência de ser preso. Me soltem, que eu não tenho paciência de ser preso". (CAMPOS, s.d.)

Esse assombro da frase do preso demonstra o peso da decisão tomada pela conveniência social, sem valor de justiça, visto que a sua motivação girou apenas em torno do fato de o menino ser filho do juiz.

Depois dessa breve exposição do conto de Moreira Campos, podemos prosseguir com a análise, levando em consideração as relações construídas ao longo da narrativa.

A priori, podemos dizer que, no conto temos, de um lado, o tabelião, o farmacêutico, além de Dr. Antero, que podem ser considerados como representantes da classe dominante. De outro lado, temos a figura de Inácio, vulgo Caroço, que estava na condição de preso. Nesse contexto, temos o que Foucault (2009) chama de práticas divisoras no trato acerca da objetivação dos sujeitos, pois observamos, nessa relação, as dicotomias inerentes ao preso, sujeito que tem em seu interior um pensamento que é contrário à circunstância na qual ele se encontra e que é mantida pela figura do Dr. Antero.

É importante ressaltar que Inácio é alvo de um poder regulamentador proporcionado pela tecnologia social que se traduz em sua prisão. Contudo, esse poder só foi efetivado porque a criança atingida pelo preso era filho do Juiz. Caso o menino não fosse filho de alguém considerado importante pela máquina social, é provável que nada houvesse acontecido com o homem. O trecho que segue evidencia isso:

Dr. Antero irritou-se:

- Isto vale nada! Soltem o pobre homem!

Inácio tomou-se de grande esperança, enquanto olhava para os que o detinham:

- Muito bem, muito bem, doutor!

- Não pode. O menino ferido é filho de Dr. Targino - falou o soldado.

- De quem?

- É filho do juiz de direito - esclareceu o farmacêutico ao lado.

- Meu velho, pra que você fez isso! - disse Dr. Antero, já sorvendo o café e perdendo um pouco do primeiro entusiasmo. (CAMPOS, s.d.) 
Podemos perceber a luta entre a condição de subjetividade do preso e a situação na qual ele se encontra. A frase "Me solte que eu não tenho paciência de ser preso" consiste em um posicionamento de resistência acerca da condição de Inácio, sujeito trabalhador, pobre, que tem na sua conduta moral uma riqueza a ser preservada, mas que se perdera com a prisão.

Vale dizer que o desprezo em relação à frase proferida por Inácio pode ser inserido no contexto de lutas que se referem à relação de poder. Diante disso, podemos analisar a figura do personagem, a partir da significação de sujeito oferecida por Foucault (2009):

Há dois significados para a palavra sujeito: sujeito a alguém pelo controle e dependência, e preso à sua própria identidade por uma consciência ou autoconhecimento. Ambos sugerem uma forma de poder que subjuga e torna sujeito a. (FOUCAUL, 2009, p. 235).

Com base no autor, podemos dizer que Inácio é sujeito ao Dr. Antero e toda a problemática relacionada ao incidente traduz-se em uma forma de transgressão de um determinado poder, relacionado à manutenção da tecnologia social que regulamenta a sociedade. Além disso, há o fato de o incidente ter ocorrido justamente com o filho do juiz. Isso é importante porque, segundo as idéias foucaultianas há:

[...] uma perpétua articulação do poder com o saber e do saber com o poder. Não podemos nos contentar em dizer que o poder tem necessidade de tal ou tal descoberta, desta ou daquela forma de saber, mas que exercer o poder cria objetos de saber, os faz emergir, acumula informações e as utiliza. (FOUCAULT, 2008, p. 80)

A isso, podemos relacionar, ainda, a ideia concernente ao sistema de diferenciações que permeiam as ações dos sujeitos. Nesse contexto, temos a condição estabelecida pela relação de poder, isto é, a prisão de Inácio, que culminou no efeito apresentado no desfecho do conto: a morte do personagem. Em suma, foi o saber de Dr. Antero acerca do menino que o fez exercer o seu poder em relação a Inácio e enviá-lo à prisão.

Nesse caso, a prisão é feita uma tecnologia disciplinar apenas pelo fato de o menino atingido por Inácio ser filho do juiz. Assim, o seu funcionamento é justificado por esse motivo, visto que ela devia fazer aparecer o poder restaurador da conduta do preso. Podemos 
destacar, entretanto, a ineficácia desse poder instrumentalizado pela prisão, com base no pensamento foucaultiano, haja vista ela não cumprir o seu papel em relação ao cidadão que deveria ter sua conduta restaurada e comete suicídio, o que consiste em um ato de resistência em relação ao poder disciplinar da prisão e da relação de poder estabelecida.

Da mesma forma, Inácio está sujeito à condição de homem subjugado pela consciência de que a situação de encarcerado consiste em uma mácula irreparável na sua constituição de sujeito que defende a lisura de caráter perante a família, pois ele é (era) exemplo de conduta moral ilibada. Vale dizer que a prisão, enquanto tecnologia disciplinar, proporciona isso.

Diante da situação, podemos relacionar à condição de Inácio na prisão ao que Foucault diz sobre o caráter solidário do encarceramento:

“[...] a solidão realiza uma espécie de auto-regulação da pena, e permite uma como que individualização espontânea do castigo: quanto mais o condenado é capaz de refletir, mais ele foi culpado de cometer seu crime; mas mais também o remorso será vivo, e a solidão dolorosa" (FOUCAULT, 1987, p. 266).

Ressaltemos, também, que a figura do advogado pode ser relacionada com a figura do Estado, pois Dr. Antero representa o sistema do direito que exerce o papel dominador em relação a Inácio. Nesse sentido, podemos analisar, no conto, os procedimentos de sujeição em relação ao preso, liderados pelo 'homem do direito'. Foucault problematiza isso quando diz o seguinte:

[...] O direito deve ser visto como um procedimento de sujeição, que ele desencadeia, e não como uma legitimidade a ser estabelecida. Para mim, o problema é evitar a questão - central para o direito - da soberania e da obediência dos indivíduos que lhe são submetidos e fazer aparecer em seu lugar o problema da dominação e da sujeição (FOUCAULT, 2008, p. 102).

Dessa forma, temos uma visão pautada na defesa de questões atinentes a determinados grupos em detrimento de outros menos favorecidos no seio da sociedade. Por isso, podemos nos reportar ao fato de o advogado mudar de opinião somente porque o menino era filho do juiz e, o homem, um mero vendedor de bananas. 
Foucault (2009) sustenta essa nossa observação ao afirmar que “[...] o Estado é considerado um tipo de poder político que ignora os indivíduos, ocupando-se apenas com os interesses da totalidade ou, eu diria, de uma classe ou um grupo dentre os cidadãos" (FOUCAULT, 2009, p. 236).

Diante do exposto, podemos dizer que Inácio, ao ser preso e manchar a sua reputação de pai de família exemplar, que via nesse fato um grande desgosto, perde o seu poder familiar, haja vista ter transgredindo uma regra que ele impunha à sua família, pois dizia: "filho meu não me dá esse desgosto".

Dessa forma, podemos afirmar que o poder familiar de Inácio foi subjugado pelo poder regulamentar do Estado, na figura do Dr. Antero, com o uso da tecnologia social pautada em sua prisão. Todavia, o preso mantém a sua luta para preservar a sua subjetividade e vence essa batalha com o suicídio. Foucault (1976) mostra-nos a morte como uma válvula de escape em relação a determinados poderes:

Enquanto, no direito da soberania, a morte era o ponto em que mais brilhava, da forma mais manifesta, o absoluto poder do soberano, agora a morte vai ser, ao contrário, o momento em que o indivíduo escapa a qualquer poder, volta a si mesmo e se ensimesma, de certo modo, em sua parte mais privada (FOUCAULT, 1976, p. 296).

Ao considerarmos o que o autor diz, estabelecendo uma relação com o desfecho do conto, entendemos que a morte de Inácio consiste em uma ferramenta de poder que atua sobre duas vertentes: primeiro, o liberta da condição de preso e restabelece sua identidade e, segundo, aprisiona as consciências dos personagens que concorreram para a sua prisão.

Dessa forma, apesar de ter sido sujeito a um determinado poder, efetivado pela figura do Dr. Antero, Inácio também exerce uma forma de poder que é preponderante para o desfecho da narrativa. Portanto, podemos dizer que o protagonista "[...] não é o outro do poder: é um de seus primeiros efeitos. O indivíduo é um efeito do poder e simultaneamente, ou pelo próprio fato de ser um efeito, é seu centro de transmissão (FOUCAULT, 2008, p. 103).

Diante desse cenário, é importante fazer, também, um contraponto em relação à noção de corpo no pensamento foucaultiano, visto que "[...] desapareceu o corpo supliciado, esquartejado, amputado, marcado simbolicamente no rosto ou no ombro, exposto vivo ou 
morto, dado como espetáculo. Desapareceu o corpo como alvo principal da repressão penal" (FOUCAULT, 1987, p. 12).

No contexto da narrativa, a punição de Inácio não se deu na sua natureza corpórea, mas sim, em sua alma e em sua consciência. O seu corpo, todavia, foi instrumento de poder para a instalação da culpa, mediante sua morte, àqueles que foram responsáveis pela sua prisão. Dessa forma, podemos relacionar esse aspecto à ideia de que "[...] o corpo traz consigo, em sua vida e em sua morte, em sua força e em sua fraqueza, a sanção de todo erro e de toda verdade como ele traz consigo também e inversamente sua origem - proveniência" (FOUCAULT, 2008 p. 15.)

Com base em Foucault (1987), podemos dizer, ainda, que a morte de Inácio consiste na perpetuação do seu suplício para com o seu corpo social. Mais que isso, resulta na transferência desse suplício para os sujeitos responsáveis pelo episódio em questão. O que temos, então, é a passagem do suplício da alma e da consciência para uma dimensão física, resultante de sua morte, que deságua nas consciências daqueles que ostentavam o sofrimento de Inácio outrora.

Por fim, podemos dizer que as relações de poder, estabelecidas ao longo da narrativa, transformam-se à medida que os acontecimentos vão se desenrolando durante o enredo. Dessa forma, essas relações estão pautadas na subjetividade dos personagens e nas lutas que eles travam para a constituição de si.

\section{CONSIDERAÇÕES FINAIS}

A nossa abordagem consistiu na análise do conto O preso, de Moreira Campos, com o objetivo de analisar como as relações de poder e as estratégias de resistência interferem na constituição dos sujeitos e na sua conduta perante a sociedade.

O que percebemos é que essas relações ocorrem de maneira hierarquizada e sob diversos aspectos, mediante o caráter capilar do poder e de suas estratégias, tendo em vista que os poderes que permeiam os sujeitos são diversos: poder político, poder familiar, poder da igreja, entre outros, que atuam na constituição dos sujeitos e compõem a arena de lutas e resistência em relação a eles.

No conto em análise, flagramos a convencionalidade do poder regulamentador e o uso da tecnologia social para a manutenção de uma dada ordem em prol de uma dada classe 
social. Da mesma forma, percebemos também o sistema de diferenciações que atua para o estabelecimento das relações de poder entre os sujeitos.

Ressaltemos, dessa forma, que as relações de poder são circunstanciais e que o lugar social dos sujeitos pode definir se elas serão estabelecidas ou não. Igualmente, é perceptível a hierarquização dos poderes que atuam sobre os sujeitos na sociedade. Um exemplo claro disso consiste no fato de o Dr. Antero mudar sua decisão depois de saber que o menino era filho do juiz.

Devemos dizer, ainda, que a análise desenvolvida não exaure as possibilidades de abordagem relativas ao escopo em questão. Com isso, é preciso considerar que outros aspectos podem ser observados, sob óticas diferentes de análise. Portanto, esperamos que essa abordagem suscite novos caminhos para a análise das relações de poder que se estabelecem e refletem os mais diversos contextos sociais.

\section{REFERÊNCIAS}

CAMPOS, J. M. M. O preso. In: Maravilhas do Conto Moderno Brasileiro. Editora Cultrix. [s.d.].

FOUCAULT, M. Vigiar e punir: nascimento da prisão. Tradução de Raquel Ramalhete. Petrópolis: Vozes, 1987.

FOUCAULT, M. Aula de 17 de março de 1976. In: Em defesa da sociedade. Curso no Collége France (1975-1976). Tradução de Maria Ermantina Galvão. São Paulo: Martins Fontes: 2005. p. 285-316.

FOUCAULT, M. Microfísica do poder. 25. ed. Tradução de Roberto Machado. São Paulo: Graal Edições 2008.

FOUCAULT, M. O sujeito e o poder. In: DREYFUS, H.; RABINOW, P. (Org.). MICHEL FOUCAULT: Uma trajetória filosófica para além do estruturalismo e da hermenêutica. 2 Edição Revista. Tradução de Vera Portocarrero e Gilda Gomes Carneiro. Rio de Janeiro: Forense Univesitária, 2009, p. 231-249.

PRADO FILHO, K. A genealogia como método histórico de análise de práticas e relações de poder. Revista de Ciências HUMANAS, Florianópolis, v. 51, n. 2, p. 311-327, jul-dez, 2017. 